\title{
Application and Optimization of Dispersive Liquid-liquid Microextraction Coupled with High-performance Liquid Chromatography for Sensitive Determination of Furfural and Hydroxymethyl Furfural in Jarred and Canned Baby-foods
}

\author{
Hossein Habibi ${ }^{1}$, Abdorreza Mohammadi ${ }^{2, *}$, Marzieh Kamankesh $^{3}$ \\ 1- Ph.D. student in Food Science and Technology, Students` Research Office, National Nutrition and Food Technology Research Institute, Faculty of \\ Nutrition Sciences and Food Technology, Shahid Beheshti University of Medical Sciences, Tehran, Iran. \\ 2- Dept. of Food Science and Technology, National Nutrition and Food Technology Research Institute, Faculty of Nutrition Sciences and Food \\ Technology, Shahid Beheshti University of Medical Sciences, Tehran, Iran. \\ 3- Ph.D. student in Spectroscopy, Micro- and Nano-extraction Laboratory, Dept. of Chemistry, Iran University of Science and Technology, Tehran, Iran.
}

\section{A B S T R A C T}

Background and Objectives: Furfural (F) and hydroxymethyl furfural (HMF) are cyclic aldehydes, which are formed during the heat processing of foods. These chemical contaminants have received much attention due to their suspected health hazards and heat damage indicators. The aim of the present study was extraction and determination of $\mathrm{F}$ and HMF in baby-foods using dispersive liquid-liquid microextraction (DLLME) coupled with high-performance liquid chromatography (HPLC).

Materials and Methods: Several effective parameters including the type and volume of extracting and disperser solvents, $\mathrm{pH}$ and salt amount were studied and optimized to find the best way of detecting and analyzing F and HMF. The optimized method was applied to determine F and HMF in 33 samples of babyfoods (powdered, soups, fruit puree and juices).

Results: According to the results of this study, the optimal experimental conditions were: 4.5 for $\mathrm{pH}, 60 \mu \mathrm{L}$ for 1-octanol, $600 \mu \mathrm{L}$ for ethanol and $2 \mathrm{~g}$ of salt $(\mathrm{NaCl})$. The limit of detection (LOD) was $1.3 \mu \mathrm{g} \mathrm{kg}^{-1}$ for F and 2.1 $\mu \mathrm{g} \mathrm{kg}^{-1}$ for HMF. F and HMF were found in all samples at levels ranging from 110 to $27510 \mu \mathrm{g} \mathrm{kg}^{-1}$ and from 200 to $25750 \mu \mathrm{g} \mathrm{kg}^{-1}$, respectively.

Conclusions: The proposed method can be considered as an effective, fast and reliable method for investigating $\mathrm{F}$ and $\mathrm{HMF}$ in baby-foods.

Keywords: Furfural, Hydroxymethyl furfural, Baby-foods, Dispersive liquid-liquid microextraction, Highperformance liquid chromatography

\section{Introduction}

2-furaldehyde or furfural (F) and 5-hydroxymethyl2-furfuraldehyde or hydroxymethyl furfural (HMF) are cyclic aldehydes (Figure 1), which are formed during the heat processing of foods.

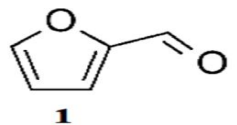

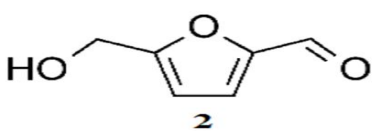

2
Figure 1. Chemical structure of furfural (1) and hydroxymethyl furfural (2).
Several reactions involved in this process are acidic decomposition of sugars, Maillard reaction and caramelization. $F$ and HMF can react further by decarboxylation, oxidation, dehydration, and reduction reactions to form melanoidins as the final Maillard reaction products (1). The European Union has legislated that the HMF content of honey after processing and/or blending shall not be more than 40 $\mathrm{mg} \mathrm{kg}^{-1}$. However, the HMF content of honey from 
countries or regions with tropical ambient temperatures shall not be more than $80 \mathrm{mg} \mathrm{kg}^{-1}$ (2). These chemical contaminants have received much attention due to their suspected health hazards and have been evaluated as volatile compounds, as well as nutritional deterioration and heat damage indicators in honey (3), fruit juices (4), milk-based infant formula, which is used for infants under six months old $(5,6)$ and baby food $(7,8)$.

A wide variety of methods and derivative techniques such as spectroscopy (9), solid-phase extraction followed by gas chromatography-mass spectrometry (4), solid-phase extraction followed by liquid chromatography-mass spectrometry (7), and solid-phase extraction coupled with liquid chromatography multi-stage mass spectrometry (10) are employed to separate and quantify $\mathrm{F}$ and $\mathrm{HMF}$ from foodstuffs. During the extraction of $F$ and $\mathrm{HMF}$ from foodstuffs, sample preparation is a critical step, and it should be able to increase sensitivity. Conventional methods, such as liquid-liquid extraction (LLE) and solid phase extraction (SPE) usually require derivatization and large volume of organic solvents. Besides, they suffer from disadvantages such as secondary waste generation, being tiresome and being time-consuming (11, 12). To overcome these problems, recent methods have focused on the development of microextraction techniques that lead to the simplification of sample preparation and minimization of organic solvent use. Typically, microextraction techniques are classified into solid-phase and liquid-phase microextraction (13, 14). Headspace solid-phase microextraction followed by gas chromatography-mass spectrometry is used for the separation and determination of $\mathrm{F}$ and $\mathrm{HMF}$ in treacle or black honey (15) and in different Italian vinegars (16). Dispersive liquid-liquid microextraction (DLLME) followed by highperformance liquid chromatography was used in the study of $\mathrm{F}$ and HMF in milk-based (powdered) infant formula (6).

DLLME was introduced by Rezaee and co-workers in 2006 (17). This technique is based on the emulsion phenomena among ternary component solvents. Emulsification is performed by injecting a mixture of the extraction and dispersion solvents in the aqueous sample, and a cloudy emulsion forms. In the emulsion, innumerable small droplets of the extraction solvent with large surface areas are dispersed into the entire aqueous sample. After a very short time, equilibrium is reached and the separation process is performed by centrifugation. The DLLME method offers the merits of low cost, easy operation, high recovery, fast extraction, environmental friendliness and capability to supply high extraction efficiency $(18,19)$. DLLME has been successfully applied for the determination of analytes in environmental water and foods (20-25).

The food factories in connection with the production of infant formula and baby foods are trying not only to improve the quality and nutritional content of their products, but also to bring the infant formula and baby food composition closer to human milk or daily needs of babies. When breastfeeding is not an option available to an infant or a baby, the role of these products is important. Baby foods unlike infant formula have more different components so that the interactions between them during the production of baby foods and storage at inadequate temperatures can lead to the creation of different furfural derivatives (7).

The aim of this research was to introduce DLLMEHPLC-UV as a fast, high selective and sensitive method for the separation and determination of $\mathrm{F}$ and HMF in baby-food samples such as powdered, readyto-eat soups, fruit puree and fruit juices. For this purpose, effective variables in the DLLME process such as $\mathrm{pH}$, type and volume of extracting and disperser solvents and ionic strength were optimized and suitable results were obtained.

\section{Materials and Methods}

Reagent, material and standards: Furfural (F) and hydroxymethyl furfural (HMF) with purity higher than $99 \%$ were obtained from Sigma-Aldrich (Steinheim, Germany). 1-octanol, ethanol, methanol, hydrochloric acid, glacial acetic acid, ammonium phosphate, sodium hydroxide, sodium chloride (analytical grade), ammonium acetate, acetic acid, and acetonitrile (HPLC grade) were obtained from Merck (Darmstadt, Germany).

Individual stock solutions of $\mathrm{F}$ and $\mathrm{HMF}$ were prepared at a concentration of $2000 \mu \mathrm{g} \mathrm{mL}^{-1}$ in methanol. For preparation of mixed standard solution with a concentration of $100 \mu \mathrm{g} \mathrm{mL}^{-1}$ for each analyte, the stock standard solutions were diluted with methanol. Working standard solutions from 0.2 to 200 $\mu \mathrm{g} \mathrm{L}^{-1}$ were prepared by diluting the stock standard solution with methanol. $10.6 \mathrm{~g}$ of potassium 
hexacyanoferrate was adjusted to $100 \mathrm{~mL}$ by purified water for preparation of Carrez solution I. $21.9 \mathrm{~g}$ of zinc acetate was added to $3 \mathrm{~mL}$ of glacial acetic acid, and then this volume was dissolved in $100 \mathrm{~mL}$ of purified water for preparation of Carrez solution II. The $\mathrm{pH}$ of the solutions was adjusted by hydrochloric acid $\left(2 \mathrm{~mol} \mathrm{~L}^{-1}\right)$. All solutions were refrigerated at $4^{\circ} \mathrm{C}$.

Instrumental conditions: The HPLC system (Cecil CE-4900, Cambridge, England) consisted of two CE4100 pumps, multiple solvent delivery unit, vacuum degasser, mixing chamber, six-port valve (Rheodyne, USA), and CE-4200 UV-Vis detector (Cambridge, England). An ODS column (250 mm 4 mm I.D., 5 $\mu \mathrm{m})$ was applied for separation of the analytes. The separation of $\mathrm{F}$ and HMF was performed at ambient temperature $\left(25^{\circ} \mathrm{C}\right)$ using an acetate buffer $\left(0.2 \mathrm{~mol} \mathrm{~L}^{-}\right.$ $\left.{ }^{1}, \mathrm{pH}=3\right)$ : acetonitrile $(85: 15)$ as mobile phase at a flow rate of $0.8 \mathrm{~mL} \mathrm{~min}^{-1}$. The injection volume was $20 \mu \mathrm{L}$. The effluent was monitored at $284 \mathrm{~nm}$ for both $\mathrm{F}$ and HMF.

Sample preparation: Baby-food samples were purchased from main supermarkets and stored at a temperature of $4^{\circ} \mathrm{C}$. One gram of the baby food sample was weighed and transferred to a conical flask, and $9 \mathrm{~mL}$ of $\mathrm{NaOH}\left(0.01 \mathrm{~mol} \mathrm{~L}^{-1}\right)$ was added to hydrolyze the sample. Then the mixture was agitated for two minutes, and $1 \mathrm{~mL}$ Carrez solution I and $1 \mathrm{~mL}$ Carrez solution II were added to the sample solution to precipitate the protein and soluble carbohydrate. After shaking for two minutes, the closed container was centrifuged for five minutes at $4000 \mathrm{rpm}$, and the supernatant was separated and filtered using a syringe filter with cellulose acetate $(0.45 \mu \mathrm{m})$. Finally, the clean aqueous phase was transferred to another conical flask, and its $\mathrm{pH}$ was adjusted to 4.5 by adding the proper amount of hydrochloric acid.

\section{Dispersive liquid-liquid microextraction}

(DLLME): $60 \mu \mathrm{L}$ of 1-octanol (extracting solvent) and $600 \mu \mathrm{L}$ of ethanol (disperser solvent) were rapidly injected into the $10 \mathrm{~mL}$ sample solution, and then $2 \mathrm{~g}$ of salt was added. The mixture was agitated for two minutes. Thereafter, the cloudy solution was centrifuged for 10 minutes at $4000 \mathrm{rpm}$. After this process, a tiny droplet of 1-octanol was floated on the aqueous sample. The lower-aqueous phase was separated, and $20 \mu \mathrm{L}$ of the floated phase was injected directly into the HPLC using a Hamilton microsyringe.

\section{Results}

In the present study, a powdered baby food sample was selected for method optimization. For determination of $\mathrm{F}$ and HMF in the baby food samples, several effective factors in the DLLMEHPLC-UV method such as $\mathrm{pH}$, type of extraction and disperser solvents and their volumes and ionic strength (amount of $\mathrm{NaCl}$ ) were optimized. The peak areas of $\mathrm{F}$ and HMF were applied as the indicator of extraction to evaluate the effect of different levels of variables for obtaining the optimal condition.

\section{Optimization of DLLME parameters}

pH effect: For examination of the effect of aqueous solution $\mathrm{pH}$ on the extraction efficiency of $\mathrm{F}$ and HMF in DLLME stage, some experiments were carried out within the $\mathrm{pH}$ range of 3-10. Other experimental conditions were kept constant. Figure 2 shows that the $\mathrm{pH}$ of aqueous solution has significant effect on the extraction of target analytes. It was found that the best efficiencies can be obtained at $\mathrm{pH}$ 4.5 .

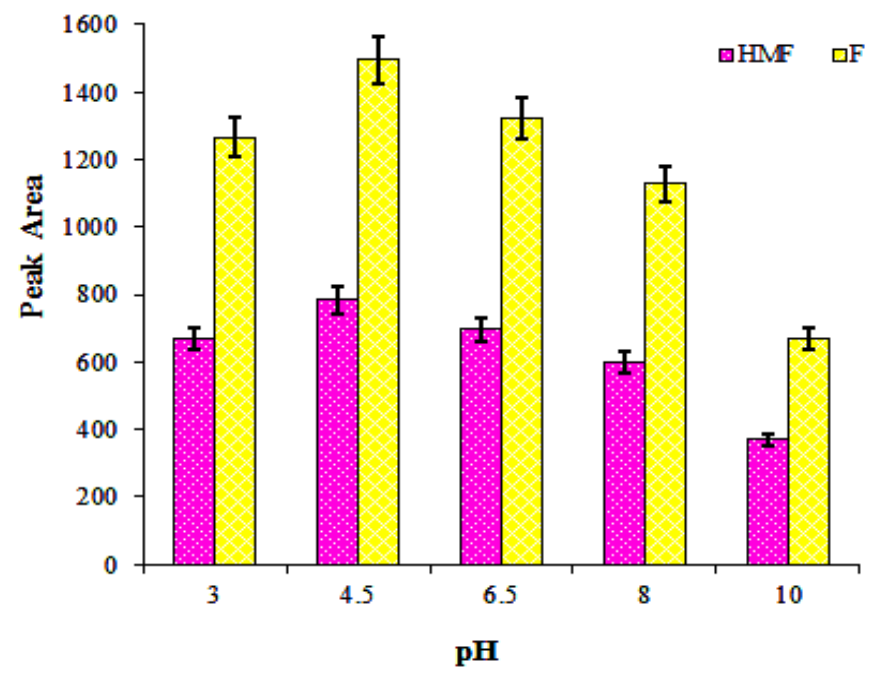

Figure 2. Effect of $\mathrm{pH}$ on extraction efficiency $(\mathrm{n}=3)$. Experimental conditions: pH: 3-10; extracting solvent: $80 \mu \mathrm{L}$; disperser solvent: $600 \mu \mathrm{L}$, and salt $1 \mathrm{~g}$.

Type and volume of extraction solvent: Two solvents, 2-ethyl-1-hexanol and 1-octanol, were tested to choose the best extracting solvent. 1-octanol was selected as the best extracting solvent, which gave maximum recovery. Different experiments were carried out by adding various volumes of 1-octanol $(40,60,80,100$ and $120 \mu \mathrm{L})$. Other experimental factors were kept in the constant condition. The extraction efficiency improved when the extraction solvent volume was increased to $60 \mu \mathrm{L}$ (Figure 3). 


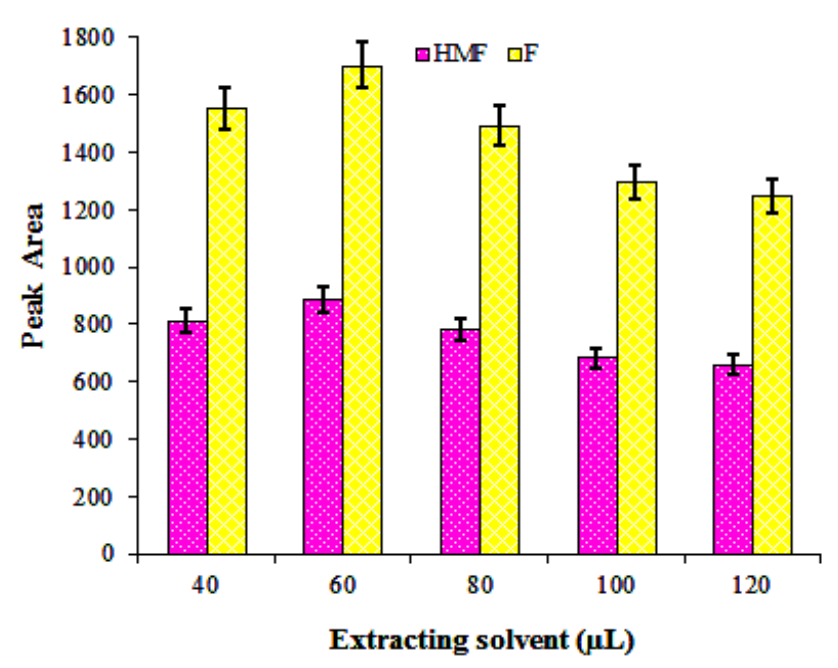

Figure 3. Effect of extracting solvent on extraction efficiency $(n=3)$. Experimental conditions: $\mathrm{pH}: 4.5$; extracting solvent: $40-120 \mu \mathrm{L}$; disperser solvent: $600 \mu \mathrm{L}$, and salt $1 \mathrm{~g}$.

Type and volume of disperser solvent: The main demand for a disperser solvent is to be miscible with both water and extraction solvent. Four organic solvents (acetonitrile, methanol, acetone and ethanol) with this characteristic were used as disperser solvents. The results indicated that ethanol had the highest effect on the distribution of $\mathrm{F}$ and HMF between the organic and aqueous phases, so ethanol was selected as appropriate disperser solvent. For optimization of ethanol volume in DLLME step, ethanol range of $300-900 \mu \mathrm{L}$ was tested. Other experimental conditions were kept constant. According to Figure 4, the ethanol volume of $600 \mu \mathrm{L}$ was chosen as the optimum disperser solvent.

Ionic strength effect: Several experiments were performed with the addition of $\mathrm{NaCl}$ in the range 0-2

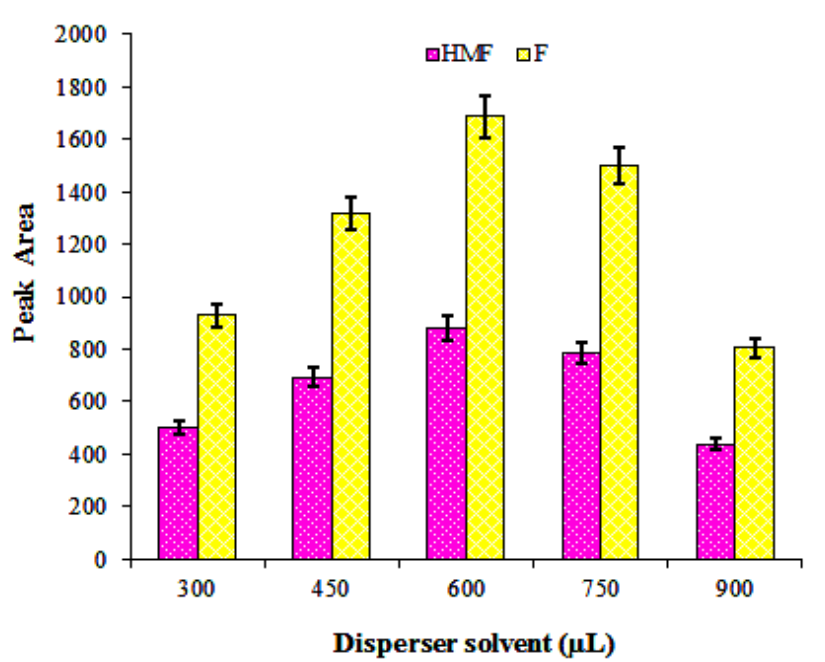

Figure 4. Effect of disperser solvent on extraction efficiency $(\mathrm{n}=3)$. Experimental conditions: $\mathrm{pH}: 4.5$; extracting solvent: $60 \mu \mathrm{L}$; disperser solvent: $300-900 \mu \mathrm{L}$, and salt $1 \mathrm{~g}$.

g. The results showed that the extraction efficiency improved with the increase of the salt amount, and maximum performance was achieved with 2 grams of salt.

According to the obtained results, the optimal experimental conditions for extraction of $\mathrm{F}$ and $\mathrm{HMF}$ from baby-food samples were: 4.5 for $\mathrm{pH}, 60 \mu \mathrm{L}$ for 1-octanol (extracting solvent), $600 \mu \mathrm{L}$ for ethanol (disperser solvent) and $2 \mathrm{~g}$ of salt $(\mathrm{NaCl})$.

The figures of merit: The merit figures of DLLMEHPLC-UV method such as linearity, repeatability, recovery, limit of detections (LODs), and limit of quantifications (LOQs) were investigated under optimal conditions (Table 1).

Table 1. The figures of merit for the proposed method and comparison with other methods

\begin{tabular}{|c|c|c|c|c|c|c|c|c|c|}
\hline Method & $\begin{array}{l}\text { Matrix of } \\
\text { baby food }\end{array}$ & Analyte & $\begin{array}{c}\text { DLR } \\
\left(\mu \mathrm{g} \mathrm{kg}^{-1}\right)\end{array}$ & $\mathrm{R}^{2}$ & $\begin{array}{l}\text { RSD } \\
(\%)\end{array}$ & $\begin{array}{c}\text { Recovery } \\
(\%)\end{array}$ & $\frac{\mathrm{LOD}}{\left(\mu \mathrm{g} \mathrm{kg}^{-1}\right)}$ & $\begin{array}{c}\mathrm{LOQ} \\
\left(\mu \mathrm{g} \mathrm{kg}^{-1}\right)\end{array}$ & Reference \\
\hline HPLC-UV $^{\mathrm{a}}$ & Fruit & HMF & $10-200000$ & - & $0.9-2.6$ & 85.0 & 30.0 & - & 22 \\
\hline $\begin{array}{l}\text { RP-HPLC- } \\
\text { UV }^{\mathrm{c}}\end{array}$ & $\begin{array}{l}\text { Fruit and vegetable } \\
\text { jarred baby food }\end{array}$ & $\mathrm{F}$ & $140-3000$ & 0.9999 & - & 90.0 & 3.5 & 11.6 & 8 \\
\hline \multirow{2}{*}{$\begin{array}{l}\text { DLLME- } \\
\text { HPLC-UV }^{\mathrm{d}}\end{array}$} & \multirow{2}{*}{$\begin{array}{l}\text { Powdered, ready- } \\
\text { to-eat soups, fruit } \\
\text { puree and juices }\end{array}$} & $\mathrm{F}$ & \multirow[t]{2}{*}{$0.2-200$} & \multirow{2}{*}{$\begin{array}{l}0.9902 \\
0.9915\end{array}$} & 4.7 & 94.6 & 1.3 & 4.4 & \multirow[t]{2}{*}{ This study } \\
\hline & & HMF & & & 5.1 & 97.8 & 2.1 & 6.7 & \\
\hline
\end{tabular}

${ }^{a}$ High-performance liquid chromatography

${ }^{b}$ Solid phase extraction-liquid chromatography-mass spectrometry

${ }^{\mathrm{C}}$ Revers phase-high performance liquid chromatography

${ }^{\mathrm{d}}$ Proposed method 
The calibration curves were linear over the range of $0.2-200 \mu \mathrm{g} \mathrm{kg}^{-1}$ with a coefficient of determination $\left(\mathrm{R}^{2}\right)$ higher than 0.9902 for both $\mathrm{F}$ and HMF. Repeatability was described as the relative standard deviation (RSD\%), and six replicate extractions from one baby food sample were employed to estimate it. RSD\% was 4.7 and $5.1 \%$ for $F$ and HMF, respectively. Recovery for each analyte was determined by comparing the amount of analyte added to a baby food sample with the concentration found after the extraction procedure. The value of recovery under optimum conditions was $94.6 \%$ and $97.8 \%$ for $\mathrm{F}$ and HMF, respectively. The LOD and LOQ (defined as the lowest concentration of the analyte in a sample) provide a chromatographic signal 3 and 10 times higher than the background noise, respectively. The LOD and LOQ were 1.3 and 4.42 $\mu \mathrm{g} \mathrm{kg}{ }^{-1}$ for $\mathrm{F}$ and 2.1 and $6.72 \mu \mathrm{g} \mathrm{kg}^{-1}$ for $\mathrm{HMF}$, respectively.

The method evaluation on real samples: To assess the practical applicability of DLLME-HPLC-UV method, 33 samples of baby-foods (15 samples of powdered, 6 samples of fruit puree, 3 samples of fruit juices and 9 samples of ready-to-eat soups) were selected. Extraction and determination of $\mathrm{F}$ and $\mathrm{HMF}$ were performed under optimum conditions. The analytical results (confirmed by the standard addition method) are summarized in Table 2. F and HMF were found in all samples at levels ranging from 110 to $27500 \mu \mathrm{g} \mathrm{kg}^{-1}$ and from 200 to $25700 \mu \mathrm{g} \mathrm{kg}^{-1}$, respectively.

Figure 5 shows the chromatograms obtained by DLLME-HPLC-UV for a baby-food sample before (a) and after (b) spiking with F and HMF in the standard solutions at a concentration level of $50 \mu \mathrm{g}$ $\mathrm{kg}^{-1}$. A clean separation and a good chromatogram were easily achieved without the presence of sample matrix interference. The results demonstrated the applicability of DLLME followed by HPLC-UV for extracting and measuring $\mathrm{F}$ and $\mathrm{HMF}$ in various babyfood samples.

Table 2. Analytical results of F and HMF in the baby food samples by DLLME-HPLC-UV method

\begin{tabular}{|c|c|c|c|}
\hline Baby foods & Main ingredients & $\mathrm{F}\left(\mu \mathrm{g} \mathrm{kg}^{-1} \times 10^{+3}\right)^{\mathrm{e}}$ & $\operatorname{HMF}\left(\mu \mathrm{g} \mathrm{kg}^{-1} \times 10^{+3}\right)^{\mathrm{e}}$ \\
\hline $\mathrm{P}^{\mathrm{a}} 1$ & Wheat flour, dry milk, date flakes & $0.47 \pm 0.010$ & $25.75 \pm 1.26$ \\
\hline $\mathrm{P} 2$ & Wheat flour, dry milk, orange, pineapple, banana & $0.54 \pm 0.020$ & $8.37 \pm 0.41$ \\
\hline P3 & Wheat flour, dry milk, honey & $0.21 \pm 0.010$ & $1.69 \pm 0.080$ \\
\hline P4 & Wheat flour, dry milk, banana slices & $0.59 \pm 0.020$ & $7.81 \pm 0.38$ \\
\hline P5 & Wheat flour, skimmed-milk powder & $0.30 \pm 0.010$ & $7.62 \pm 0.37$ \\
\hline P6 & Wheat flour, dry milk & $2.20 \pm 0.080$ & $6.10 \pm 0.29$ \\
\hline P7 & Wheat flour, skimmed-milk powder, natural banana powder & $0.24 \pm 0.010$ & $18.19 \pm 0.89$ \\
\hline P8 & Rice flour, dry milk & $0.44 \pm 0.010$ & $1.00 \pm 0.040$ \\
\hline P9 & Rice flour, dry milk, natural banana powder & $0.37 \pm 0.010$ & $9.09 \pm 0.44$ \\
\hline $\mathrm{P} 10$ & Wheat flour, dry milk, honey & $1.08 \pm 0.040$ & $2.80 \pm 0.13$ \\
\hline $\mathrm{P} 11$ & Rice flour, dry milk, almond & $0.19 \pm 0.010$ & $1.19 \pm 0.050$ \\
\hline $\mathrm{P} 12$ & Rice, wheat, maize, barley and rye flour, dry milk, banana & $12.71 \pm 0.49$ & $0.95 \pm 0.040$ \\
\hline $\mathrm{P} 13$ & Almond powder, rice flour & $5.78 \pm 0.22$ & $0.37 \pm 0.010$ \\
\hline $\mathrm{P} 14$ & Almond powder, dry milk, rice flour & $27.51 \pm 1.070$ & $0.37 \pm 0.010$ \\
\hline $\mathrm{P} 15$ & Cereals, cocoa powder & $7.90 \pm 0.30$ & $16.9 \pm 0.65$ \\
\hline $\mathrm{F}^{\mathrm{b}} 1$ & Apple, banana, strawberry puree & $5.80 \pm 0.22$ & $14.23 \pm 0.69$ \\
\hline F2 & Apple, banana, blueberry puree & $4.07 \pm 0.15$ & $10.05 \pm 0.49$ \\
\hline F3 & Black plum, apple puree & $14.77 \pm 0.57$ & $19.87 \pm 0.97$ \\
\hline $\mathrm{F} 4$ & Apple, kiwi, pineapple puree & $3.31 \pm 0.12$ & $1.33 \pm 0.060$ \\
\hline F5 & Apple, strawberry, cherry, yogurt, rice, maize flour & $4.76 \pm 0.18$ & $16.86 \pm 0.82$ \\
\hline F6 & Apple puree & $9.93 \pm 0.38$ & $25.58 \pm 1.25$ \\
\hline $\mathrm{D}^{\mathrm{c}} 1$ & Apricot, pear juice & $4.49 \pm 0.17$ & $8.89 \pm 0.43$ \\
\hline D2 & Apple, orange, peach juice & $3.09 \pm 0.12$ & $9.35 \pm 0.45$ \\
\hline D3 & Apple, orange juice & $2.60 \pm 0.10$ & $10.70 \pm 0.52$ \\
\hline$S^{\mathrm{d}} 1$ & Carrot, chicken & $1.77 \pm 0.060$ & $0.37 \pm 0.010$ \\
\hline S2 & Carrot, Ham & $0.42 \pm 0.010$ & $0.20 \pm 0.010$ \\
\hline S3 & Green vegetables, chicken & $0.27 \pm 0.010$ & $0.35 \pm 0.010$ \\
\hline S4 & Zucchini, beef & $0.16 \pm 0.010$ & $0.68 \pm 0.030$ \\
\hline S5 & Green vegetables, rice, salmon & $0.28 \pm 0.010$ & $0.35 \pm 0.010$ \\
\hline S6 & Carrot, pea, veal & $0.12 \pm 0.020$ & $0.41 \pm 0.020$ \\
\hline S7 & Potato, zucchini, pasta, ham & $5.56 \pm 0.21$ & $0.71 \pm 0.030$ \\
\hline S8 & Zucchini, pea, rice, chicken, carrot & $0.26 \pm 0.010$ & $0.60 \pm 0.020$ \\
\hline S9 & Potato, milk, ham, parsnip, leeks & $0.11 \pm 0.010$ & $0.41 \pm 0.020$ \\
\hline
\end{tabular}



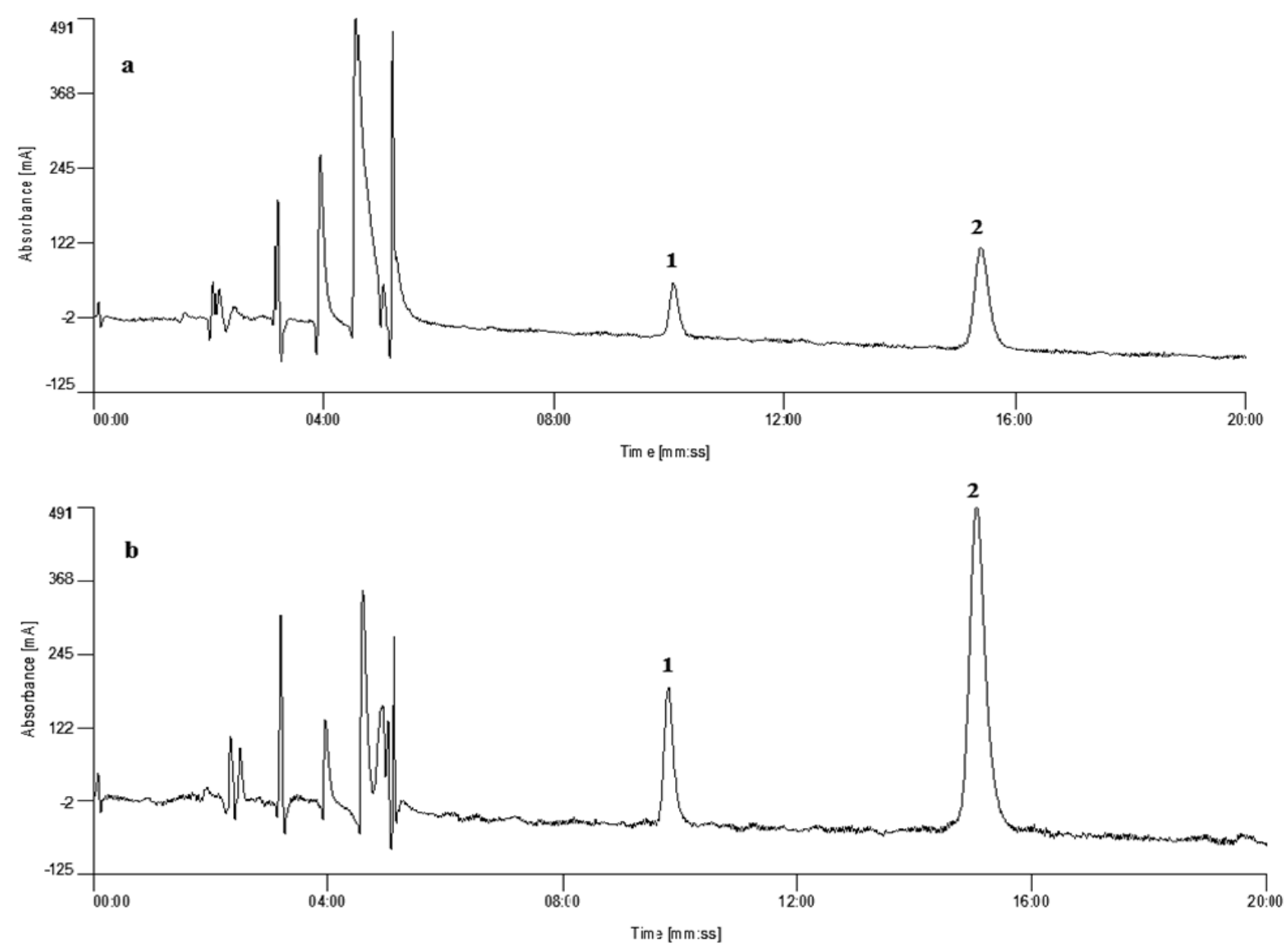

Figure 5. The chromatogram obtained by DLLME-HPLC-UV for a baby-food sample (P3) under optimum conditions: (a) non-spiked, and (b) spiked with $50 \mu \mathrm{g} \mathrm{kg}^{-1}$ of (1) HMF and (2) F.

\section{Disc ussion}

Optimization: The $\mathrm{pH}$ performs an important role in transferring the target analytes into the organic phase. According to Figure 2, it seems that in $\mathrm{pH}$ equal to 4.5, the structure of $\mathrm{F}$ and HMF are suitable for extracting by 1 -octanol.

Chlorinated solvents as extraction solvents are used in most applications of DLLME procedure. These solvents have higher density than water, and the separated organic extract is collected from the bottom of the sample tube with a syringe. This technique has some disadvantages as well such as environmental toxic problem. Also for HPLC analysis, the extract demands evaporation and reconstitution in a suitable solvent, which increases the analysis time and the risk of analyte losses. In DLLME, an extraction solvent has several characteristics such as being immiscible with water, not interfering with the analytical methods used, good chromatographic behavior, and high solubility in disperser solvent, as well as low toxicity, low volatility and low cost. From a chemical point of view, the affinity of long chain alcohols (1-octanol, 1undecanol, 1-dodecanol and 2-dodecanol) is not very different for a special analyte or a group of analytes, and sometimes, different alcohols are suitable for extraction of the same compound(s). According to these findings, 2-ethyl-1-hexanol and 1-octanol were considered as extraction solvents. As shown in Figure 3 , the extraction efficiency improves when the extraction solvent volume is increased to $60 \mu \mathrm{L}$, which could be due to increase in concentration of $\mathrm{F}$ and HMF in 1-octanol. It is noticed that the volume of extraction solvent lower than $60 \mu \mathrm{L}$ was difficult to handle for collecting the extraction phase.

According to Figure 4, low volume of ethanol reduces the extraction efficacy, probably because the droplets of 1-octanol (extracting solvent) are not shaped well. The solubility of analytes in aqueous phase may be increased by adding more than $600 \mu \mathrm{L}$ of ethanol that eventually causes a decrease in the extraction efficiency. 
The addition of $\mathrm{NaCl}$ to the aqueous sample can significantly improve the extraction of several analytes in DLLME method. It could be due to the partition of hydrophobic analytes between the aqueous and organic phases as a result of the salting out effect. We expected that adding $\mathrm{NaCl}$ would lead to an increase in the ionic strength and transmission power of the non-polar analyte in the sample solution. The extraction efficiency improved with the increase of the salt amount, and maximum performance was achieved with 2 grams of salt. The high concentration of salt can reduce the diffusion rates of the analytes into the organic phase, which, in turn, decreases the extraction efficiency of $\mathrm{F}$ and HMF from the aqueous phase to organic phase. On the other hand, analytes cannot be quickly desorbed and distributed into the dispersed organic phase as a result of slow mass transfer. A longer extraction time is also needed to achieve equilibrium in these conditions. According to these findings, 2 grams of salt was used to obtain the highest extraction efficiency.

Validation: Analysis of $\mathrm{F}$ and HMF showed a linear relationship with high linear regression coefficients of determination $\left(\mathrm{R}^{2}>0.9902\right)$ for both $\mathrm{F}$ and HMF. The results indicated that the proposed method is comparable to other methods (Table 1).

Real sample analysis: The present study confirms the results of other researchers that $F$ and HMF form during food processing $(7,8,26,27)$. Average value of HMF in the powdered (milk-based and cereal based) baby foods was in accordance with the levels reported in previous studies (from non-detectable to $57180 \mu \mathrm{g} \mathrm{kg}^{-1}$ ) (7). The F and HMF levels in the fruitbased baby foods were higher than those of the readyto-eat soups and powdered baby-foods probably due to high carbohydrate content and low $\mathrm{pH}$ of the fruitbased baby foods. The HMF contents of fruit-based baby foods (1330-25580 $\left.\mu \mathrm{g} \mathrm{kg}^{-1}\right)$ are in agreement with the results reported by Č́žzová et al. (27), who achieved a value of $4100-28900 \mu \mathrm{g} \mathrm{kg}^{-1}$ for HMF, but the amount of $\mathrm{F}$ is more in several samples. The mean concentrations of $\mathrm{F}$ and HMF in the fruit-based baby foods are higher than those reported by some researches $(8,26)$, who obtained a value of nondetectable to $1820 \mu \mathrm{g} \mathrm{kg}^{-1}$ for $\mathrm{F}$ and a value of 140 to $9590 \mu \mathrm{g} \mathrm{kg}^{-1}$ and 2100 to $9800 \mu \mathrm{g} \mathrm{kg}^{-1}$ for HMF. The diversity in the amount of $\mathrm{F}$ and HMF can be related to differences in the type of processing and storage time in the baby-food samples.
The aim of the present research was to propose a sensitive and efficient method for simultaneous extraction and determination of trace amounts of $\mathrm{F}$ and HMF from powdered, ready-to-eat soups and fruit-based baby-food samples. The DLLME was successfully applied to rapid isolation and preconcentration of the target analytes prior to analysis by high-performance liquid chromatography. To achieve maximum extraction efficiency, effective parameters were optimized. The proposed DLLMEHPLC-UV method, because of its simplicity, high sensitivity, analytical precision, high recovery, low consumption of organic solvents and short extraction time, has the ability to be a good alternative to other techniques. Also it is capable to extract and determine a very low level of $\mathrm{F}$ and HMF from various complex food matrices.

\section{Financial disclosure}

The authors declared no financial interest.

\section{Funding/Support}

This study has been supported by the National Nutrition \& Food Technology Research Institute of Iran (NNFTRI). We gratefully acknowledge their assistance.

\section{References}

1. Antal Jr MJ, Mok WS, Richards GN. Mechanism of formation of 5-(hydroxymethyl)-2-furaldehyde from Dfructose and sucrose. Carbohyd Res. 1990;199(1):91109.

2. Directive 2001/110/EC of 20 December 2001 (2001). Official Journal of the European Communities, 47-52.

3. Nozal MaJ, Bernal JL, Toribio L, Jiménez JJ, Martín MaT. High-performance liquid chromatographic determination of methyl anthranilate, hydroxymethylfurfural and related compounds in honey. J Chromatogr A. 2001;917(1):95-103.

4. Teixidó E, Santos FJ, Puignou L, Galceran M. Analysis of 5-hydroxymethylfurfural in foods by gas chromatography-mass spectrometry. J Chromatogr A. 2006;1135(1):85-90.

5. Chávez-Servín JL, Castellote AI, López-Sabater MC. Evolution of potential and free furfural compounds in milk-based infant formula during storage. Food Res Int. 2006;39(5):536-43.

6. Madani-Tonekaboni M, Kamankesh M, Mohammadi A. Determination of furfural and hydroxymethyl furfural from baby formula using dispersive liquid-liquid microextraction coupled with high performance liquid chromatography and method optimization by response 
surface methodology. J Food Compos Anal. 2015;40:17.

7. Gökmen V, Senyuva HZ. Improved method for the determination of hydroxymethylfurfural in baby foods using liquid chromatography-mass spectrometry. J Agr Food Chem. 2006;54(8):2845-9.

8. Mesias-Garcia M, Guerra-Hernández E, García-Villanova $\mathrm{Bn}$. Determination of furan precursors and some thermal damage markers in baby foods: ascorbic acid, dehydroascorbic acid, hydroxymethylfurfural and furfural. J Agr Food Chem. 2010;58(10):6027-32.

9. Motiyenko RA, Alekseev EA, Dyubko SF. Microwave spectroscopy of furfural in vibrationally excited states. J Mol Spectrosc. 2007;244(1):9-12.

10. Teixidó E, Moyano E, Santos FJ, Galceran MT. Liquid chromatography multi-stage mass spectrometry for the analysis of 5-hydroxymethylfurfural in foods. $\mathbf{J}$ Chromatogr A. 2008;1185(1):102-8.

11. Buldini PL, Ricci L, Sharma JL. Recent applications of sample preparation techniques in food analysis. J Chromatogr A. 2002;975(1):47-70.

12. Habibi H, Mohammadi A, Hoseini H, Mohammadi M, Azadniya E. Headspace liquid-phase microextraction followed by gas chromatography-mass spectrometry for determination of furanic compounds in baby foods and method optimization using response surface methodology. Food Anal Method. 2013;6(4):1056-64.

13. Jeannot MA, Przyjazny A, Kokosa JM. Single drop microextraction-development, applications and future trends. J Chromatogr A. 2010;1217(16):2326-36.

14. Habibi H, Mohammadi A, Mohammadi M, Amiri Z, Azadniya E. Determination of furanic compounds in baby-foods in Tehran market using the microextraction technique and effects of preparation temperature on their concentration. Iran J Nutr Sci Food Technol. 2013;8(1):241-52.

15. Edris AE, Murkovic M, Siegmund B. Application of headspace-solid-phase microextraction and HPLC for the analysis of the aroma volatile components of treacle and determination of its content of 5-hydroxymethylfurfural (HMF). Food Chem. 2007; 104(3):1310-4.

16. Giordano L, Calabrese R, Davoli E, Rotilio D. Quantitative analysis of 2-furfural and 5-methylfurfural in different Italian vinegars by headspace solid-phase microextraction coupled to gas chromatography-mass spectrometry using isotope dilution. J Chromatogr A. 2003;1017(1):141-9.

17. Rezaee M, Assadi Y, Milani Hosseini M-R, Aghaee E, Ahmadi F, Berijani S. Determination of organic compounds in water using dispersive liquid-liquid microextraction. J Chromatogr A. 2006;1116(1):1-9.

18. Berijani S, Assadi Y, Anbia M, Milani Hosseini M-R, Aghaee E. Dispersive liquid-liquid microextraction combined with gas chromatography-flame photometric detection: Very simple, rapid and sensitive method for the determination of organophosphorus pesticides in water. J Chromatogr A. 2006;1123(1):1-9.

19. Pirsa S, Alizadeh N. Rapid determination of pyridine derivatives by dispersive liquid-liquid microextraction coupled with gas chromatography/gas sensor based on nanostructured conducting polypyrrole. Talanta. 2011;87:249-54.

20. Yamini Y, Rezaee M, Khanchi A, Faraji M, Saleh A. Dispersive liquid-liquid microextraction based on the solidification of floating organic drop followed by inductively coupled plasma-optical emission spectrometry as a fast technique for the simultaneous determination of heavy metals. J Chromatogr A. 2010;1217(16):2358-64.

21. Abedi A-S, Mohammadi A, Azadniya E, Mortazavian AM, Khaksar R. Simultaneous determination of sorbic and benzoic acids in milk products using an optimised microextraction technique followed by gas chromatography. Food Addit Contam. 2014;31(1):21-8.

22. Aeenehvand S, Toudehrousta Z, Kamankesh M, Mashayekh M, Tavakoli HR, Mohammadi A. Evaluation and application of microwave-assisted extraction and dispersive liquid-liquid microextraction followed by high-performance liquid chromatography for the determination of polar heterocyclic aromatic amines in hamburger patties. Food Chem. 2015;190:429-35.

23. Nojavan Y, Kamankesh M, Shahraz F, Hashemi M, Mohammadi A. Ion pair-based dispersive liquid-liquid microextraction followed by High performance liquid chromatography as a new method for determining five folate derivatives in Foodstuffs. Talanta. 2015;137:31-7.

24. Kamankesh M, Mohammadi A, Hosseini H, Tehrani ZM. Rapid determination of polycyclic aromatic hydrocarbons in grilled meat using microwave-assisted extraction and dispersive liquid-liquid microextraction coupled to gas chromatography-mass spectrometry. Meat Sci. 2015;103:61-7.

25. Bashiry M, Mohammadi A, Hosseini H, Kamankesh M, Aeenehvand S, Mohammadi Z. Application and optimization of microwave-assisted extraction and dispersive liquid-liquid microextraction followed by high-performance liquid chromatography for sensitive determination of polyamines in turkey breast meat samples. Food Chem. 2016;190:1168-73.

26. Vorlova L, Borkovcova I, Kalabova K, Vecerek V. Hydroxymethylfurfural contents in foodstuffs determined by HPLC method. J Food Nutr Res. 2006;45(1):34-8.

27. Č́źžková H, ŠevČ́́k R, Rajchl A, Voldřich M. Nutritional quality of commercial fruit baby food. Czech J Food Sci. 2009;27:134S-S7. 